\title{
Beyond Vision: Data as Art
}

The ongoing quest to gather data leads to more tools and techniques for portraying phenomena in ways that are scientifically revealing and, as it turns out, beautiful. In this way, data are becoming a new category of art. Following is an array of scientific images chosen for their composition, color, and form, along with their scientific significance. Their aesthetic characteristics tell scientific, technological, and sometimes social and cultural stories.

IVAN AMATO

Ivan Amato is a science writer whose articles have been published in several magazines and newspapers, including Time, Fortune, and U.S. News \& World Report. He is an associate editor for Science News and author of a book on materials science, Stuff: The Materials the World Is Made of (BasicBooks, 1997), which was chosen as a New York Times Notable Book in 1997. His book Super Vision: A New View of Nature (Harry N. Abrams, New York, 2003) comes out next month.

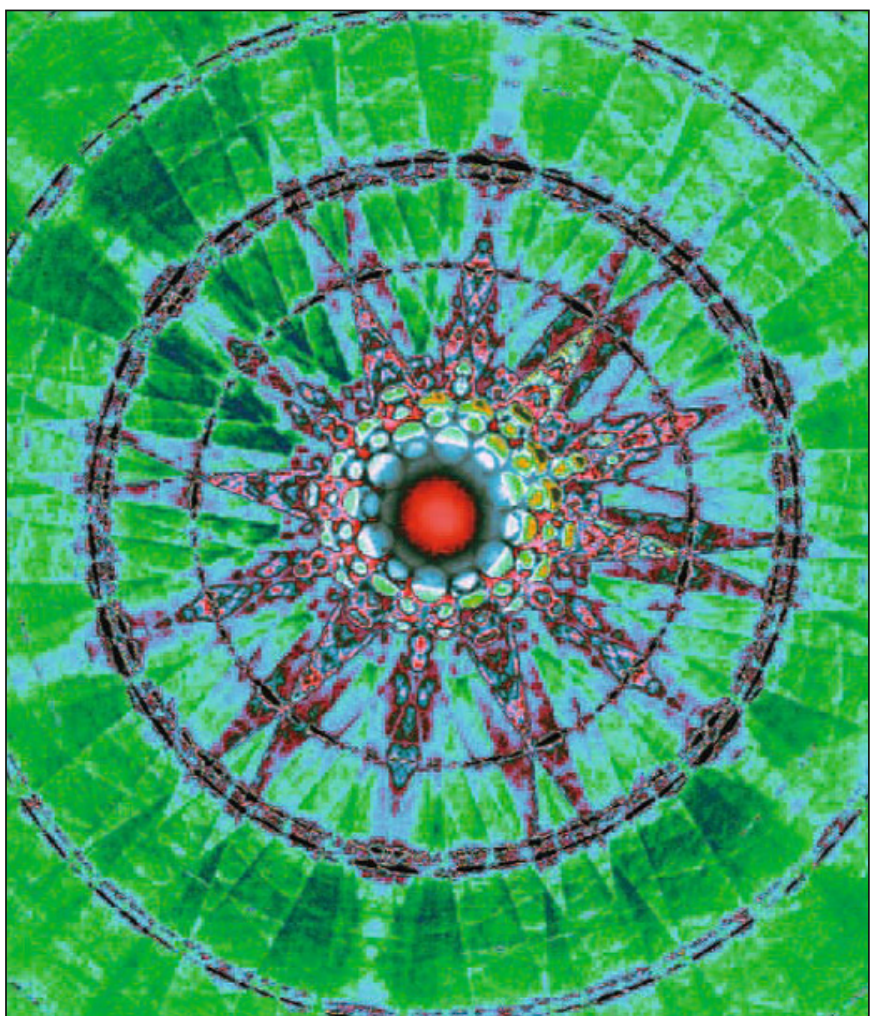

\section{Crystal Mandala}

Description: With false colors, this convergent-beam electron diffraction (CBED) image of lanthanum aluminate $\left(\mathrm{LaAlO}_{3}\right)$, a ceramic substrate that in the 1980s helped rekindle research in superconductivity, looks like it ought to be hanging above a couple of lava lamps with the Grateful Dead rock band playing in the background. Working with the specific features of the image, such as the concentric disks and the radial forms, researchers can discern the sample's crystal structure. The lattice constant of $\mathrm{LaAlO}_{3}$ is $5.357 \AA$.

Courtesy: Paul Midgley, University of Cambridge

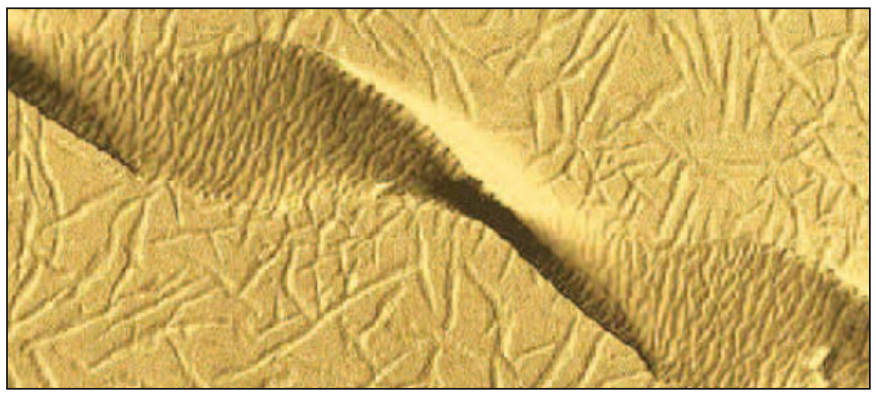

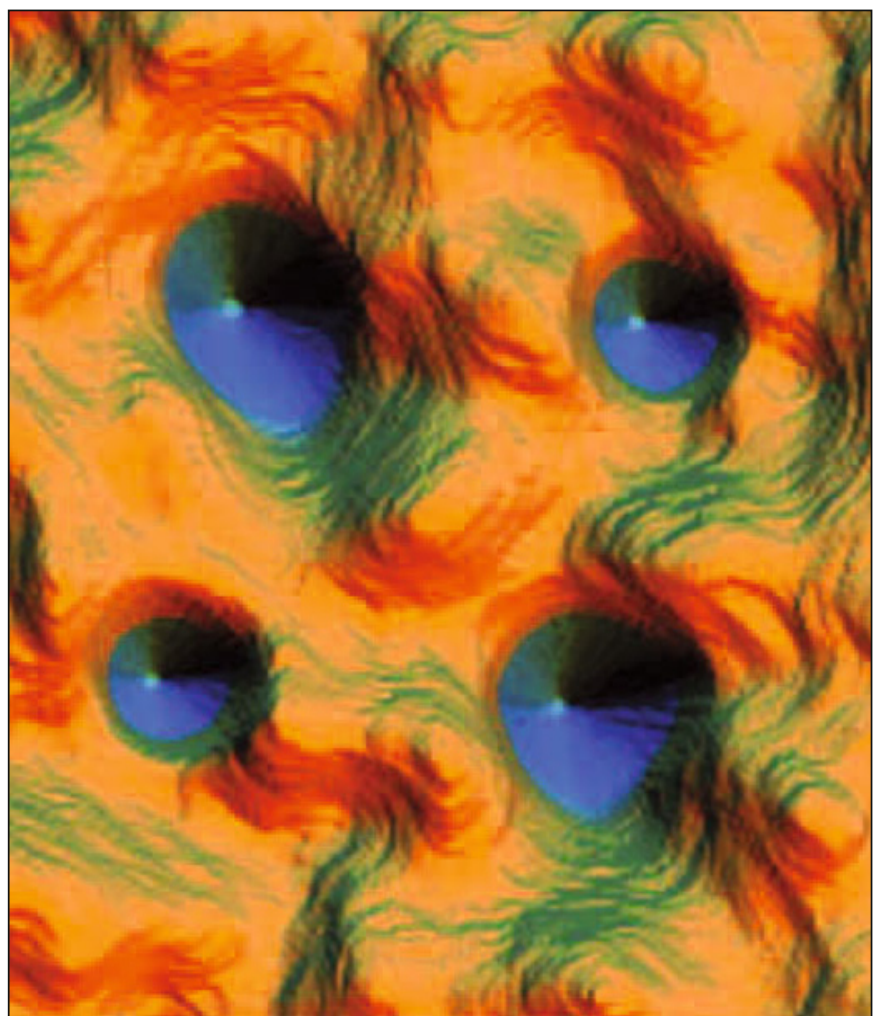

\section{Still Life with Cobalt and Copper}

Description: With a scanning tunneling microscope and an attractive choice of colors at their disposal, researchers at the National Institute of Standards and Technology generated some atomic portraiture worthy of framing. The larger mounds correspond to pairs of cobalt atoms, the smaller ones to single cobalt atoms - all of them on a background of copper. The cobalt atoms amount to a magnetic impurity that influences electrons near the copper surface. These electronic effects show up as green and red squiggly lines. The image is $\sim 8 \mathrm{~nm}$ across.

Courtesy: Joseph A. Stroscio, Robert J. Celotta, Aaron P. Fein, Eric W. Hudson, and Steven R. Blankenship, National Institute of Standards and Technology

\section{Twisted Crystal}

Description: When researchers synthesized a polymer using chiral monomers, as biology does in the construction of biopolymers such as proteins and DNA, they observed this stunning helical result. The structure emerges from a hierarchy of microstructures: About 2000 monomers string together and then repeatedly double back on one another to form a single lamella; these lamellae then stack by the thousands, like a deck of cards. A slight rotation between adjacent lamellae sums into a helical architecture. The helix is on the order of $1 \mu \mathrm{m}$ wide.

Courtesy: Stephen Z.D. Cheng and Christopher Y. Li, University of Akron 


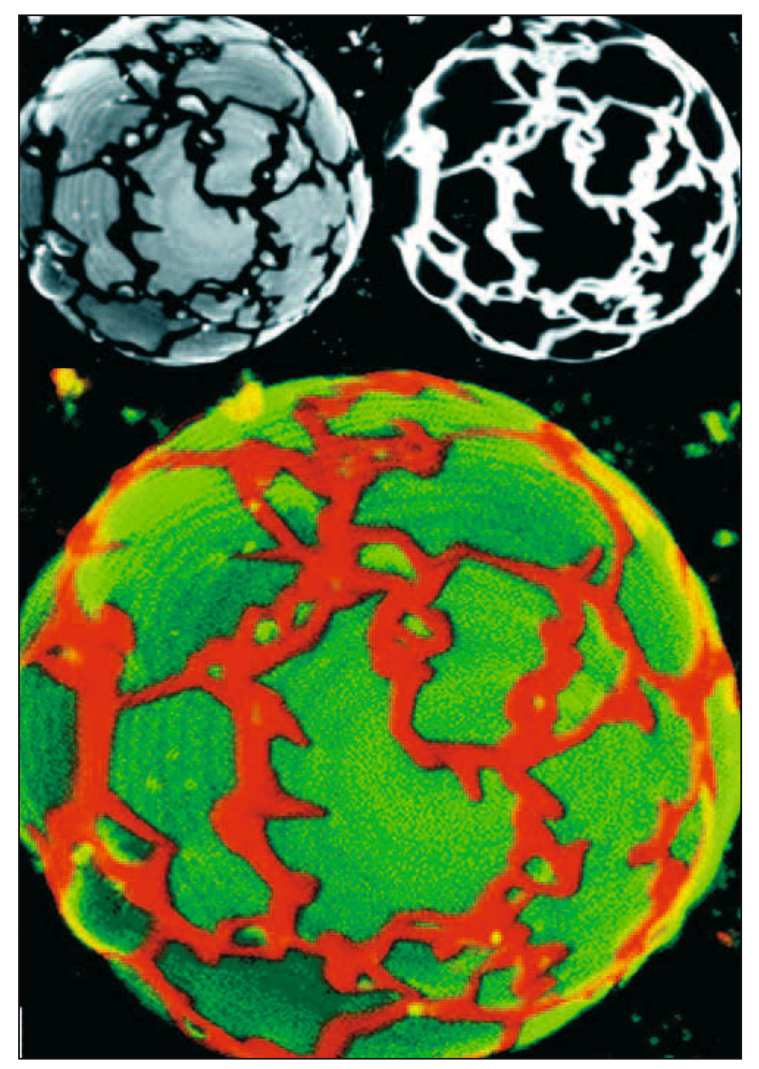

\title{
Planet Fat
}

Description: Take some cholesterol and mix it with two types of lipid molecules-one with four times as many carbon atoms than the other-and you end up with a giant unilamellar phospholipid vesicle. Otherwise known as GUVs, these structures serve as fine models for cellular membranes. By using laser scanning confocal microscopy and fluorescent dyes, it is possible to label each type of lipid and reveal its distribution throughout the GUV. The shorter lipids are fluorescing in the upper left image and the longer ones are shining in the upper right. By merging the data and adding color, a GUV can look like a most intriguing moon. The GUVs are $\sim 20 \mu \mathrm{m}$ in diameter.

Courtesy: Gerald W. Feigenson, Cornell University

\section{Flower Crystal}

Description: Inside the cells of many flowering plants are crystalline inclusions known as druses. This one, from the Peperomia astrid plant, is a carnation-like assemblage of calcium oxalate crystals, a substance also found in ceramic glazes and kidney stones. In plants, it is possible that druses like these help gather light for photosynthesis. The diameter of the druse structure is $\sim 10 \mu \mathrm{m}$.

Courtesy: Harry T. (Jack) Horner, Iowa State University

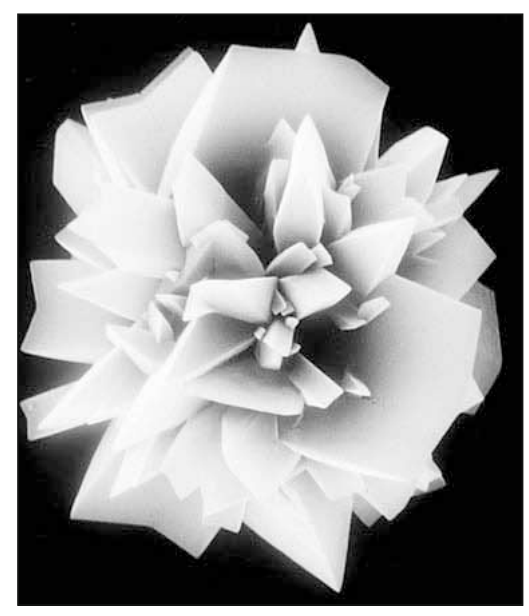

\section{MRS FALL MEETING}

\author{
TUESDAY, DECEMBER 2
}

2:30 pm- Atomic Force Acoustical Microscopy (AFAM) and High Throughput

3:30 pm Combinatorial Microscopy: Two New Approaches for Analyzing Advanced Materials

\section{-000 seminars}

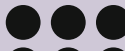

As a complement to the 2003 MRS Fall Meeting, the Materials Research Society is pleased to continue Research Tools Seminars, an exciting educational program that will focus on the scientific basis and practical application of commercially available, state-of-the-art tools for materials research.

Held in the Exhibit Hall and free-ofcharge to meeting attendees, these one-hour seminars will describe a technical approach to meet a paricular challenge, as embodied in commerically-available products or tools.

\section{NANOTECH-AMERICA • SPRINGFIELD, MA}

3:30 pm- Automated Standard Porosimeter

4:30 pm POROTECH LTD. • ONTARIO, CANADA

\section{WEDNESDAY, DECEMBER 3}

10:30 am- Advanced Methods for Characterization of Magnetic Materials

11:30 am QUANTUM DESIGN, INC. • SAN DIEGO, CA

2:30 pm- New Tools for Nanotechnology Research

3:30 pm VEECO INSTRUMENTS INC. - WOODBURY, NY

3:30 pm- Epitaxial Deposition of Thin Film Layers Using Cutting-Edge MOCVD Technology

4:30 pm EMCORE CORPORATION • SOMERSET, NJ 